\title{
MANOEL DE BARROS - A PAISAGEM E A LINGUAGEM
}

\author{
Dóris Helena Soares da Silva Giacomolli ${ }^{1}$ \\ Antônio Carlos Mousquer ${ }^{2}$
}

\begin{abstract}
RESUMO: Nesta leitura da obra de Manoel de Barros, onde se sobressai a paisagem do pantanal matogrossense, tentaremos identificar a relação que existe em seu trabalho, e sua apreensão dessa paisagem por uma nova combinação de palavras e figuras de linguagem. num intentar não somente de representar o sujeito-lírico interior, mas que o percebe, por fim, derramar-se na paisagem; "liquefazejar-se", num trabalho poético que é mais a fixação de uma nova imagem do que o poeta vê que propriamente uma descrição dessa paisagem. Realçaremos, especialmente, o diálogo dos seus textos com as palavras, buscando conhecer alguns recursos utilizados pelo autor no seu fazer poético, no qual os objetos e seres rasteiros ao derredor "animizam-se." O poeta desliza sobre as palavras, como as lesmas sobre seu líquido que, ao moverem-se, vão abandonando sob o corpo parte desse líquido, diminuindo, assim, o atrito por onde passam. Assim o faz o poeta Manoel de Barros: transforma o universo cotidiano em palavras, o lugar-comum em poesia e nesse espalhar-se, sossega das atribulações; espraia-se e projeta-se enquanto subjetividade lírica.
\end{abstract}

Palavras-chave: Manoel de Barros. Michel Collot. Natureza-paisagem. Palavras. Poesia.

ABSTRACT: In this reading of the Manoel de Barros' work, where the landscape of the Mato Grosso marshland stands out, we will try to identify the relation that exists in his work, and his apprehension of this landscape by a new combination of words and figures of language. in an attempt not only to represent the inner lyrical subject, but which perceives it, at last, to pour into the landscape; "become liquid" in a poetic work that is more the fixation of a new image that the poet sees than properly a description of this landscape. We will especially emphasize the dialogue of his texts with the words, seeking to know some resources used by the author in his poetic making, in which objects and creeping beings around "animate themselves." The poet slides over the words, like the slugs on their liquid that, when they move, leave behind part of that liquid, thus reducing the friction where they pass. So does the poet Manoel de Barros: he transforms the everyday universe into words, the commonplace in poetry and in this spread, quiet of tribulations; spreads and projects himself as lyrical subjectivity.

Keywords: Manoel de Barros. Michel Collot. Nature-landscape. Words. Poetry.

1 Doutoranda em História da Literatura na FURG. E-mail: dorishssg@gmail.com.

2 Professor Associado da Universidade Federal do Rio Grande. E-mail: antoniomousquer@furg.br. 


\title{
1 INTRODUÇÃO
}

Tentei descobrir na alma alguma coisa mais profunda do que não saber nada sobre as coisas profundas.

Consegui não descobrir. Manoel de Barros

A primeira vez que li Manoel de Barros, Livro das ignoranças (1994) senti que o mundo podia ser simples, que uma pessoa poderia derreter, escorrer pelos muros, igual à gosma das lesmas, numa sensação próxima ao surrealismo e aos relógios moles de Salvador Dali. Quem escreveria coisas como: "Respeito as oralidades. Eu escrevo o rumor das palavras."!? - Manoel de Barros, o poeta do Pantanal. Meu sentimento foi de surpresa, de bicho que escorrega de dentro da casca para se mostrar a um universo de prazer:

\author{
Toda vez que encontro uma parede \\ ela me entrega às suas lesmas. \\ Não sei se isso é uma repetição de mim ou das lesmas. \\ Não sei se isso é uma repetição das paredes ou de mim. \\ Estarei incluído nas lesmas ou nas paredes? \\ Parece que lesma só é uma divulgação de mim. \\ Penso que dentro de minha casca \\ não tem um bicho: \\ Tem um silêncio feroz. \\ Estico a timidez da minha lesma até gozar na pedra (BARROS, 1994)
}

Como achar palavras para falar sobre a poesia de Manoel de Barros? Em suas próprias palavras, em entrevista dada a André Luís Barros, Manoel de Barros não está procurando expressar-se através da poesia, mas tentando apenas encontrar-se: "Sou um ser abúlico, tenho minhas contradições e tento me encontrar através da poesia." (BARROS, 1996, p. 1)

Tentando encontrar-se, Manoel de Barros dialoga com os objetos e seres rasteiros ao derredor, numa dimensão fugidia, fazendo-os "animizarem-se" não intentando, com isso, somente representar seu sujeito interior, mas termina por fazê-lo. Por fim, quando se derrama na paisagem; "liquefazeja-se." A palavra anima é originária do latim e pode ser traduzida por alma. A raiz latina animus é cognato em grego de anemos, vento, respiração; e do sânscrito aniti, ele respira. Em italiano e espanhol, a palavra ânima é traduzida como alma. É essa alma que transborda nos poemas do poeta pantaneiro, nos deixando num sentimento de ambiguidade, em outra percepção da realidade. Porque colocou sua alma a observar o que o rodeava, deixou-a transbordar e contagiar os objetos ao derredor, encantou-se e encantou: "Passava os dias ali, quieto, no meio das coisas miúdas. E me encantei."

Porque olha, Manoel de Barros nos faz olhar também, porque sente, o poeta espalha esse sentimento que vai além da paisagem que o rodeia, faz com que chegue até nós, os leitores, pois "a poesia de Manoel de Barros nos encaminha para as relações entre a palavra e

3 Trecho de entrevista Manoel de Barros faz do absurdo sensatez, ao Jornal Estado de São Paulo em 18.10.1997. 
as coisas, típica da poesia moderna, e responde a ela com uma semântica diferenciada. Para o poeta, estudar a poesia é mergulhar no espaço do mundo. Olhando para as coisas que o cercam, o poeta sente." (GONÇALVES, 2012, p.20)

À medida que uma lesma anda, abandona sob o corpo parte do líquido, o que diminui o atrito com as folhas ou a madeira por onde ele passa. Guardando as diferenças mas comparando, na mesma proporção, Manoel de Barros, apropriado para a vida em ambientes úmidos, vai colocando as palavras no papel e vai transformando o mundo num lugar mais suave e harmonioso, aparando arestas e deixando um rastro brilhante que marca por onde passou.

\section{MANOEL DE BARROS}

Nascido em Cuiabá no Mato Grosso, em 19 de dezembro de 1916, à beira do Rio Cuiabá, fazendeiro, advogado e poeta, assim Manoel de Barros se significa:

Eu tenho um ermo enorme dentro do olho. Por motivo do ermo não fui um menino peralta. Agora tenho saudade do que não fui. Acho que o que faço agora é o que não pude fazer na infância. Faço outro tipo de peraltagem. Quando eu era criança eu deveria pular muro do vizinho para catar goiaba. Mas não havia vizinho. Em vez de peraltagem eu fazia solidão. Brincava de fingir que pedra era lagarto. Que lata era navio. Que sabugo era um serzinho mal resolvido e igual a um filhote de gafanhoto.

Cresci brincando no chão, entre formigas. De uma infância livre e sem comparamentos. Eu tinha mais comunhão com as coisas do que comparação.

Porque se a gente fala a partir de ser criança, a gente faz comunhão: de um orvalho e sua aranha, de uma tarde e suas garças, de um pássaro e sua árvore. Então eu trago das minhas raízes crianceiras a visão comungante e oblíqua das coisas. Eu sei dizer sem pudor que o escuro me ilumina. É um paradoxo que ajuda a poesia e que eu falo sem pudor. Eu tenho que essa visão oblíqua vem de eu ter sido criança em algum lugar perdido onde havia transfusão da natureza e comunhão com ela. Era o menino e os bichinhos. Era o menino e o sol. O menino e o rio. Era o menino e as árvores. (BARROS, 2010, s/n)

O poeta se descobre e se encontra num tempo longínquo, quando a criança que era se apropria do seu ser e, num amálgama com a natureza, se faz paisagem; fazendo-se paisagem, reconstrói aquilo que vê, inventa e rearranja a paisagem, se mescla, se acha, comunga.

São muitos a descrever e biografar Manoel de Barros. Falar desse poeta faz com que as pessoas passem a comungar desse mesmo mundo mágico e brilhante, dos seres e de coisas cristalinas e transparentes, diáfanas e vivas, das lesmas e sapos, das árvores e dos pássaros pantaneiros. 
Vieira (2009) assim se refere a Manoel de Barros e a essa mescla do humano com a paisagem vista por Manoel de Barros:

Proveniente de uma região considerada de periferia no contexto cultural brasileiro, Manoel de Barros é um poeta mato-grossense, cuja obra tem como cenário o Pantanal, um mundo mágico que se revela por meio de coisas banais em seu estado primitivo. [...] No Pantanal de Barros se mesclam o humano, o animal, o vegetal e o mineral; água, terra e ar se penetram, tudo apodrece e renasce ao mesmo tempo. O ambiente pantaneiro, deste modo, não é apenas um pano de fundo pitoresco, e sim material a ser reinventado e transformado, assim como a infância e os seres do chão, temas geradores de sua poética. (VIEIRA, p. 10, 2009)

A própria biografia do poeta Manoel de Barros é uma poesia, escrita por ele, quando tenta descrever-se, contar-se. Ele próprio é um dos seres observáveis:

Não sou biografável. Ou, talvez seja. Em dez linhas. Nasci em Cuiabá, 1916, dezembro. Me criei no Pantanal de Corumbá. Só dei trabalho e angústias pra meus pais. Morei de mendigo e pária em todos os lugares da Bolívia e do Peru. Morei nos lugares mais decadentes por gosto de imitar os lagartos e as pedras. Publiquei dez livros até hoje. Não acredito em nenhum. Me procurei a vida inteira e não me achei - pelo que fui salvo. Sou fazendeiro e criador de gado. Não fui pra sarjeta porque herdei. Gosto de ler e de ouvir música - especialmente Brahms. Estou na categoria de sofrer do moral, porque só faço poesia (BARROS, Rio de Janeiro, 2006) $)^{4}$

\section{MICHEL COLLOT E A PAISAGEM}

Segundo Michel Collot, paisagem não é a natureza, pura e simplesmente, mas o que tem existência própria.

Collot é professor de Literatura Francesa na Universidade de Sorbonne Nouvelle - Paris III. Ele conduz o centro de pesquisas da Universidade, o departamento chamado Escritas da Modernidade, de onde propõe ao leitor um novo olhar sobre a relação do homem com a natureza, diferente daquele do período romântico onde a natureza interagia com o eu lírico, já que a natureza, no Romantismo, expressava aquilo que o eu-lírico estava sentindo no momento narrado, podendo estar presente desde as estações do ano, como formas de passagens, às tempestades, ou dias de muito sol. Em Collot (2013) "a paisagem provoca o pensar e que o pensamento se desdobra como paisagem" (COLLOT, 2013, p.12). A literatura, para Michel Collot, reflete a relação entre o homem e a paisagem:

A paisagem aparece, assim, como uma manifestação exemplar da multidimensionalidade dos fenômenos humanos e sociais, da interdependência do tempo e

4 Contracapa do livro Poemas rupestres. 
do espaço e da interação da natureza e da cultura, do econômico e do simbólico, do indivíduo e da sociedade. A paisagem nos fornece um modelo para pensar a complexidade de uma realidade que convida a articular os aportes das diferentes ciências do homem e da sociedade (COLLOT, 2013, p.15).

Paisagem é, antes de tudo, um modo de ver, uma relação própria de cada um com o mundo exterior, quanto mais não seja, um ponto de vista único. Ao estar nessa presença, o poeta vê como que ideias a lhe surgir, pois "a paisagem é um espaço percebido, ligado a um ponto de vista." (COLLOT, 2013, p. 17) Nesta visão do mundo, única, o poeta vê o que está fora, vê "um ambiente não é suscetível a se tornar uma paisagem senão a partir do momento em que é percebido por um sujeito.” (COLLOT, 2013, p. 19) Porquanto afirma Collot (2013) em Pensamento-paisagem: a paisagem aparece "como um lugar de emergência de uma forma de pensamento", pois "a experiência sensível é fonte de sentidos." (COLLOT, p.21) Além do horizonte há um mundo que se pode ver e todo ele é paisagem. Como o mundo lhe é manifestado vai expressar sua subjetividade, seu modo de ver.

O pensamento-paisagem é um trabalho de imaginação, o que não se alcança, mas o que se imagina. É um ato perceptivo, muito particular, é o que não se enxerga, uma forma de pensamento, não podendo ser percebido somente como imagem estática, fixa, mas também o som, o cheiro e o tato. É a quebra da dicotomia da objetividade e subjetividade, é a saída em direção ao mundo, quando o sujeito-lírico vai para fora, em direção ao mundo e há uma transfusão entre ele e o que percebe. "A paisagem não é apenas vista, mas percebida por outros sentidos, cuja intervenção não faz senão confirmar e enriquecer a dimensão subjetiva desse espaço" (COLLOT, 2013, p. 26)

Em Manoel de Barros se vê não o sujeito que se expressa num foro íntimo, mas que se encontra; não aquele que expressa o estado de alma, mas que olha para a paisagem e vê uma abertura, uma natureza que se expressa, que se mostra. "A experiência da paisagem, revelando a secreta continuidade que une o mundo ao corpo e o corpo ao espírito, convida-nos a redefinir as relações entre natureza e cultura. Essa experiência resulta de uma interação entre o corpo, o espírito e o mundo, e se inscreve no prolongamento das trocas que nosso organismo mantém com o meio natural (COLLOT, 2013, p. 40) O poeta não está no contexto da flora e da fauna, não é um elemento da paisagem que melhor exalta a sua realidade, mas um ser que olha e que empresta sua alma ao que vê, um sujeito que é tocado e afetado por ela, que procura nela a humanização: "Quisera humanizar de mim as paisagens. [...]Que eu possa cumprir esta tarefa, sem que o meu texto seja engolido pelo cenário." (BARROS, 2000). A paisagem não expressa aquilo que o eu-lírico está sentindo no momento narrado, mas, ao contrário, o eu-lírico expressa a natureza, a vida e alma, mostra aquilo que esta sente no momento narrado; é o resultado de uma interação a que se refere Collot (2013). Como observa Vieira (2009), dessa interação poeta Manoel de Barros-natureza, a paisagemnatureza é reinventada e demudada pelos olhos do poeta,

No Pantanal de Barros se mesclam o humano, o animal, o vegetal e o mineral; água, terra e ar se penetram, tudo apodrece e renasce ao mesmo tempo. $\mathrm{O}$ ambiente pantaneiro, deste modo, não é apenas um pano de fundo pitoresco, e sim 
material a ser reinventado e transformado, assim como a infância e os seres do chão, temas geradores de sua poética. (VIEIRA, p. 10 2009)

A linguagem de Manoel de Barros é um dos elementos que o poeta lança mão para interagir com a natureza, para refletir sobre ela, a partir do seu campo de visão particular.

Em Barros, a poesia local dá origem a um linguajar inovador, repleto de neologismos, que, no limite da agramaticalidade, liga a língua portuguesa a suas raízes mais profundas, a seus mistérios mais primitivos, instaurando um mundo tão novo como o que existia no momento seguinte ao da criação, ainda não organizado, em metamorfose, em estado de nascimento. (VIEIRA, pp. 10-11, 2009)

Essa interação com a natureza-paisagem, por meio do discurso poético, se dá de tal maneira que ele é capaz de transmutá-la em lugar idílico, comparável ao paraíso adâmico.

\title{
4 MANOEL DE BARROS DÁ ALMA À NATUREZA-PAISAGEM
}

\author{
"Em poesia que é voz de poeta, \\ que é a voz de fazer nascimentos \\ o verbo tem que pegar delírio.” \\ Manoel de Barros
}

O eu-lírico interage com a natureza, emprestando-lhe o seu mais puro estado de espírito: "Eu tenho que essa visão oblíqua vem de eu ter sido criança em algum lugar perdido onde havia transfusão da natureza e comunhão com ela. Era o menino e os bichinhos. Era o menino e o sol. O menino e o rio. Era o menino e as árvores." (BARROS, 2010) ${ }^{5}$ Andrade Jr. (2004-05) associa a escritura do poeta à visualidade, assemelhando o trabalho poético ao trabalho fotográfico, que é menos a reprodução do que vê, e muito mais descobrir uma realidade que os nossos olhos não capturam.

A poesia aí nasce da observação de uma paisagem comum, a da Cordilheira dos Andes, distante e perdida no horizonte, capaz, no entanto, de provocar a inspiração poética, que não advém como uma iluminação e sim como uma iluminura (como um pequeno ornato), que nos sugere a importância do detalhe na obra de Barros. Seu olhar procura sempre o pequeno, o sem importância, e dessa forma transgride o lugar-comum da poesia grandiloquente. $\mathrm{O}$ verso que nasce da iluminura parece representar o olhar de um fotógrafo que enquadra a paisagem e vê a realidade como um desenho composto por linhas. Por isso, a imagem poética é a transgressão da imagem perfeita (ANDRADE JR. p.3, 2004-2005)

5 Notas de orelha; Comentários sobre o autor. 
Nessa fixação de construir uma imagem pelas palavras, o poeta percebe não o grandioso, mas o pequeno, as coisas do chão.

Manoel de Barros é um pesquisador infatigável de novas fórmulas, um inventor de um novo código, uma nova maneira de expressar-se, na busca da perfeição da linguagem e da pureza original. Através da recriação da linguagem, combinando palavras, cria imagens estampadas nas páginas poéticas; novas imagens, significados e valores de um conhecido mundo, reinventando-o, fazendo-o novo, como em seus primórdios:

O poeta manipula a linguagem para "desformar" o mundo e reconstruí-lo pela palavra poética, trazendo uma nova perspectiva de olhar o mundo, plena de liberdade, de uma imaginação sem limites. E a imagem é o recurso para transcender a linguagem. O poema, em sua coexistência dinâmica com os contrários, diz mais do que a verdade, ele cria a verdade; ele não descreve a coisa, ele a coloca diante de nós. (VIEIRA, p. 16, 2009)

Um exemplo é o poema Ruína, onde o poeta mostra sua ânsia em reconstruir, construir o que foi desconstruído:

Um monge descabelado me disse no caminho: "Eu queria construir uma ruína. Embora eu saiba que ruína é uma desconstrução. Minha ideia era de fazer alguma coisa ao jeito de tapera. Alguma coisa quer servisse para abrigar o abandono, como as taperas abrigam. Porque o abandono pode não ser apenas de um homem debaixo da ponte, mas pode ser também de um gato no beco ou de uma criança presa num cubículo. $\mathrm{O}$ abandono pode ser também de uma expressão que tenha entrado para o arcaico ou mesmo de uma palavra. Uma palavra que esteja sem ninguém dentro. ( $\mathrm{O}$ olho do monge estava perto de ser canto.) Continuou: digamos a palavra AMOR. A palavra amor está quase vazia. Não tem gente dentro dela. Queria construir uma ruína para a palavra amor. Talvez ela renascesse das ruínas, como o lírio pode nascer de um monturo." E o monge se calou descabelado. (BARROS, 2005, p. 31)

Coube ao poeta tratar as palavras, acariciá-las, transformá-las, dar-lhe um novo tratamento artístico, para transmutá-las numa magnífica e surpreendente forma. No documentário Só dez por cento é mentira, $(2008)^{6}$

Manoel de Barros comenta seu trabalho poético, nos diz que, quando publica um livro, fica vazio, oco, por uns cinco meses e só volta a escrever quando o vazio desaparece para dar espaço a "um novo estado de espírito". Então escreve duzentos ou trezentos versos, para deles conseguir extrair trinta que lhe agrade; diz ele que "escrever é cortar" e conta, para ilustrar, que um escritor italiano, querendo ser poeta, escreveu um livro de poemas e ao começar a cortar as palavras excedentes, sobra somente uma. Escrevemos, diz Manoel de Barros, para tentar atingir a perfeição e para isso se deve cortar palavras, "tem que cortar na carne, tem que doer, tem eu sair sangue, a perfeição está nos detalhes.”

6 Site oficial: http://www.sodez.com.br/ URL do vídeo: https://youtu.be/xvz14rthe3M 
O poeta pantaneiro descreve como reúne as palavras, aleatoriamente, e que depois de recolhê-las, as escolhe, seleciona as que ficarão mais próximas ou mais afastadas, fazendo surgir, dentre as escolhidas, uma epifania, num reinventar da realidade. Compara sua poesia a uma aparição súbita, um aparecimento já em essência das variações e alterações das realidades linguísticas:

Se estou em estado de ânimo, vou enchendo uns cadernos com idioma escrito. Anoto tudo. Não tenho método nem métodos. Se encontro um caracol passeando na parede, anoto. Uma coisa vegetal que nasce no abdômen de um muro, anoto. Falas de bêbados e de crianças. Resíduos arcaicos pregados na língua. Pedaços de coisas penduradas no ralo. Os relevos do insignificante. A solidão de Vivaldi. Corolas genitais. Estafermos com indícios de árvore. Vespas com olho de lã. Homem na mesa interrompido por uma faca. Pessoas afetadas de inúteis e de limos. Ovuras de larvas transparentes mas antes de serem ideias. Desvios fonéticos, semânticos, estruturais, achados em leituras. Pessoas promíscuas de águas e pedras. Uma frase encontrada em Guimarães Rosa: 'A poesia nasce de modificações das realidades linguísticas'. Para o poeta a frase é uma epifania. Anoto guardadores de teriscos (mistura de teréns com cisco). Pessoas que têm gala em seu amanhecer. O osso de uma fala minada de harpas. Ponho no caderno tudo que habita à minha beira. Hesíodo. Lama gemente e ávida. Um útero de lanhos brancos. O próprio viveiro de ínfimos. Um canteiro de vermes estrábicos. No meu caderno, a lua encosta uma casa no morro - e a dorme. Existem muitas mágicas desse tipo. No começo era o verbo. O verbo era sem sujeito. Depois vieram as borboletas, as prostitutas e as virtudes teologais. Pintavam coisas rupestres com bisons. A esse tempo nem os Persas e nem os Medas conheciam bem os despejos dos esgotos. Esperavam Homero. Homens entravam e saíam dos crepúsculos carregando pedras para fazer pirâmides. O verbo foi-se encarnando. Hoje o homem tem partes com peixe. E estuda a perfeição de seus aniquilamentos. Também eu ponho no caderno trastes, pregos enferrujados, formigas carregadeiras. Se a arte é o homem acrescentado à natureza - como escrevia Van Gogh a seu irmão Théo -, eu preciso de desreinar também. Preciso de ser de outros reinos; o da água, o das pedras, o do sapo. Tudo isso botava névoas no meu caderno. Ali até se enficavam patos. Esse chão de poleiro perturba a ordem gramatical e o entendimento entre os homens. Anoto tropos. Palavras que normalmente se rejeitam, eu caso, eu himeneio. Contiguidades anômalas, seguro com letras marcadas em meu caderno. De repente uma palavra me reconhece, me chama, me oferece. Eu babo nela. Me alimento. Começo a sentir que todos aqueles apontamentos têm a ver comigo. Que saíram dos meus estratos míticos. As palavras querem me ser. Dou-lhes à boca o áspero. Tiro-lhes o verniz e os voos metafísicos. Corto o desejo de se exibirem às minhas custas. As palavras compridas se devem cortar como nós de lacraia. O verso balança melhor com palavras curtas. Os ritmos são mais variados se você trabalhar com dissílabos, com monossílabos. Exemplo: 'Parou bem de frente pra tarde um tordo tor-to'. São 30, são 50 cadernos de caos. Precioso admi- 
nistrar esse caos. Preciso imprimir vontade estética sobre esse material. Não acho a clave, o tom de entrada. Não acho o tempero que me apraz. O ritmo não entra. Há um primeiro desânimo. Aparecem coisas faltando. Um nariz sem venta. Um olho sem lua. Uma frase sem lado. Procuro as partes em outros cadernos. Dou com aquele caracol subindo na escada. E era aquele mesmo, do primeiro caderno, que então passeava uma parede. Percebo que existe uma unidade existencial nos aponta- mentos. Uma experiência humana que se expõe aos pedaços. Meus cadernos começam a criar nódoas, cabelos. As ervas sobem neles. Caretas palavras estão doentes de mim. Minhas rupturas estão expostas. Quem pode responder pelas rupturas de um poeta senão a sua linguagem? Tenho que domar a matéria. O assunto não pode subir no poema como erva. Desprezo o real, porque ele exclui fantasia. O erotismo do chão se enraíza na boca. Aproveito do chão assonâncias, ritmos. Aproveito do povo sintaxes tortas. Guardo sugestões de leituras. Estruturo os versos. E só dou por acabado um poema se a linguagem conteve o assunto nas suas devidas escolhas. As nossas particularidades só podem ser universais se comandadas pela linguagem. Subjugadas por um estilo. E isso é tão velho como abrir janelas. Acho, por fim, que jamais alcançaremos o veio da criação. As palavras embromam em vez de aclarar. O poço está cada vez mais escuro e mais fundo. Até a eternidade. Amém (BARROS, apud BORGES e TURIBA, 1989, p. 40).

Só as palavras não são suficientes para que Manoel de Barros possa expressar seu universo; as palavras dele "aprenderam a gostar do cisco, isto é, da palavra cisco" e até, e inclusive, com ela, faz poesia. (MARTINS, 2008) Na poética de Manoel de Barros há uma nova maneira de expressão, onde se misturam uma velha linguagem, palavras esquecidas, o arcaico do sertanejo, do pantaneiro, com o culto, palavras clássicas da língua:

O encanto das frases de Manoel provém dessa fusão da linguagem arcaica do homem do sertão com a melhor tradição clássica da língua: "Fico louvoso". Vá o leitor aos dicionários em busca desse adjetivo. Talvez não o encontre. Pois Manoel de Barros sabe onde e como inventar. De um músico ${ }^{7}$, ouvi certa vez uma definição da arte de Manoel de Barros: "ele abre a linguagem por dentro, e a deixa escancarada” Não encontro forma mais acabada de dizer o essencial. (MÜLLER JR., 2003, p.277)

Da metalinguagem, a linguagem que descreve sobre ela mesma, que se utiliza do próprio código para explicar-se, Manoel de Barros faz amplo uso para exprimir sua arte de compor através de versos; usa da própria palavra para descrever sua obra: "Uso a palavra para compor meus silêncios." E afirma que gosta mais das palavras novas, pois não gosta "das palavras fatigadas de informar." Diz Maria Cristina de Aguiar Campos em seu trabalho Manoel de Barros: O demiurgo das terras encharcadas que o trabalho do poeta consiste em "em valorizar e recuperar o que ele denomina de virgindade das palavras" e, para isso "se conecta a uma nostalgia da unidade mítica perdida entre homem e natureza," (CAMPOS,

7 O músico é Paulo Brandão, do extinto Aquarela Carioca. 
2007, p. 215) provocando uma inovação vocabular, fazendo poesia com e sobre a linguagem. O artesão da poética gosta de se expressar por meio de metáforas, figura de linguagem que produzam sentidos figurados, comparações implícitas e duplos sentidos.

A profusão de metáforas em seus livros tira o fôlego e remete a uma esfera mental de analogias inusitadas. Ele nos engana com o propósito explícito de criar 'inutensílios', quando na verdade vai tecendo uma teia sutil de signos sobre a fala primal da natureza 'quase' selvagem. Não há como escapar das tramas da cultura. $\mathrm{O}$ poeta busca sempre a gênese da linguagem, sua estrutura íntima, o isomorfismo entre verbo e carne - a pureza desde sempre perdida e reconstruída no imaginário coletivo (DAMAZIO, 1993).

A metáfora, comparação abreviada em que o conectivo comparativo não está expresso, mas subentendido, vem fazer parte constante do universo dos poemas do escritor sul-mato-grossense. A escritura poética manoelina nos apresenta a uma placidez que tem mãos: "A placidez já põe a mão nas águas" (BARROS, 1994) e a uma chuva que pode modificar as cores: "A chuva deformou a cor das horas." (BARROS, 1994), e a uma voz que tem chão: "No chão de minha voz tem um outono." (BARROS, 1994) Assim, através de novas formas e aproximações, Manoel de Barros consegue uma representação do que não se tem uma imagem.

Podemos relacionar o vocábulo animismo, no sentido de dar alma ou ânimo, ao fazer poético de Manoel de Barros, às suas construções originais que dão vida ao tempo que vai e não volta, pois "o tempo só anda de ida, (MARTINS, 2008) e corpo ao silêncio: "No ermo o silêncio encorpa-se." (BARROS, 1994) "Se o tempo não é humano, eu humanizo. Amarro o tempo no poste para ele parar. Boto a Manhã de pernas abertas para o sol. Me horizonto para os pássaros. Uma ave me sonha. O dia amanheceu aberto em mim.” (MARTINS, 2008) No poema mundo pequeno, de O livro das ignorãças, o poeta mostra um horizonte capaz de enrubescer e besouros que pensam: "Aqui, se o horizonte enrubesce um pouco, os besouros pensam que estão no incêndio." (BARROS, 2004, p.75) Assim, o tempo, o mundo, o silêncio, a manhã, os besouros e o dia adquirem novos poderes, uma nova alma, tornam-se seres vivos que realizam, que fazem.

Ao aproximar elementos diferentes, o poeta cria novas ideias, novos sentimentos, outro jeito de enxergar a natureza-paisagem, a natureza-inocência, uma natureza que faz, que ensina, inocentemente: "A inocência da natureza humana ou vegetal ou mineral me ensinaram mais. Quem não conhece a inocência da natureza não se conhece.” (MARTINS, 2008)

\section{CONCLUSÃO}

A experiência da paisagem é analisada pela sua disposição de acender um arrebatamento, é a saída em direção ao mundo - pensamento de poeta lírico - e que, nessa saída, vê o mundo aproximar-se de seu interior. Manoel de Barros escreve o que vê, o que sonha, o que se lhe manifesta; as paisagens presentes no cerne do seu ser, mas que não se desassocia 
de seu eu, não se desprende do mundo, não se separa de si. Quanto aos seus procedimentos estilísticos e temáticos ele os utiliza para nos revelar uma natureza-paisagem em transmutação, repleta de manifestação da vida humana, uma natureza surreal e primitiva, que se põe a falar, a sentir e a ensinar.

Se paisagem é um modo de ver, uma relação própria de cada um com o mundo exterior, o ponto de vista de Manoel de Barros é único. Na presença da paisagem, ele a descreve, as ideias lhe surgem, ela começa a ser o espaço percebido por Manoel de Barros, um espaço ligado a um ponto de vista, único, mágico. A paisagem fornece ao poeta um modelo para pensar a complexidade de uma realidade, e ao fazê-lo, o poeta faz dela uma nova imagem, mágica, criada pelo trabalho de imaginação; não o que se alcança, mas o que se imagina.

\section{REFERÊNCIAS BIBLIOGRAFIA ELETRÔNICA}

ANDRADE JR., Antonio Francisco de. Com olhos de ver: poesia e fotografia em Manoel de Barros. Cadernos de Letras da UFF - PIBIC - GLC, nos 30-31, 2004-2005. Disponível em: http://www.uff.br/ cadernosdeletrasuff/30-31/artigo4.pdf.

MÜLLER JR. Adalberto. Manoel de Barros: O avesso visível. REVISTA USP, São Paulo, n.59, p. 275279, junho/agosto 2003 Disponível em: file://C:/Users/D\%C3\%B3ris/Downloads/13295-16268-1-PB. pdf.

BARROS, André Luís. O tema da minha poesia sou eu mesmo. Jornal do Brasil. Caderno Ideias. Entrevista, Rio de Janeiro, 24 ago. 1996. Disponível em: https://www.escritas.org/pt/t/4780/o-tema-daminha-poesia-sou-eu-mesmo.

CASTELLO, José. Manoel de Barros busca o sentido da vida. O Estado de São Paulo. Caderno 2. Disponível em: http://www.secrel.com.br/jpoesia/castel11.html.

GONÇALVES. Wellington Bueno. Manoel de Barros: o poeta das coisas sem importância. Uma poesia sobre nada, Curitiba, 2012. Disponível em: http://repositorio.roca.utfpr.edu.br/jspui/ bitstream/1/1245/1/CT_LBHN_VII_2012_20.pdf.

MARTINS Bosco. Entrevista com Manoel de Barros: Três momentos com um gênio. 2014. Publicada na edição 117 da revista Caros Amigos, em 2008. Disponível em: https://www.carosamigos.com.br/index. php/grandes-entrevistas/2675-manoel-de-barros.

SILVA. Fernanda Martins da. Pensando a Tênue fronteira entre História e Literatura a partir da Obra do Poeta Manoel de Barros. Anais do XXVI Simpósio Nacional de História - ANPUH São Paulo, julho 2011 Disponível em: http://www.snh2011.anpuh.org/resources/anais/14/1301010704_ARQUIVO_ anaisanpuh2011sp.pdf. 


\section{REFERÊNCIAS BIBLIOGRÁFICAS}

BARROS, Manoel de. Para encontrar o azul eu uso os pássaros. Cuiabá: 2000.

BARROS, Manoel de. O livro das ignorãças. Rio de Janeiro: Record, 2004.

BARROS, Manoel. Ensaios fotográficos. Rio de Janeiro: Record, 2005.

BARROS, Manoel de. Poemas Rupestres. Rio de Janeiro: Best Seller, 2006.

BARROS, Manoel de. Menino do Mato. São Paulo: Leya, 2010.

BARROS, Manoel de. Memórias inventadas - As Infâncias de Manoel de Barros. São Paulo: Planeta, 2010.

BORGES, João; TURIBA. Manoel de Barros, Bric-à-Brac, [s.l.], p. 35-41, 1989.

CAMPOS, Maria Cristina de Aguiar. Manoel de Barros: O demiurgo das terras encharcadas. São Paulo: Universidade de São Paulo, 2007.

CASTRO, A. de. A poética de Manoel de Barros: a linguagem e a volta à infância. Campo Grande: FUCMT-UCDB, 1992.

COLLOT, Michel. Pensamento e paisagem. In:_ poética e filosofia da paisagem. Rio de Janeiro: Oficina Raquel, 2013.

COLLOT, Michel. Paisagem e literatura. In:_ poética e filosofia da paisagem. Rio de Janeiro: Oficina Raquel, 2013.

COLLOT, Michel. Lugares românticos e descrição poética. In:_ poética e filosofia da paisagem. Rio de Janeiro: Oficina Raquel, 2013.

COLLOT, Michel. O sujeito lírico fora de si. Tradução de Alberto Pucheau. Terceira margem. Revista do progrma de pós graduação em ciência da literatura. Universidade Federal do Rio de Janeiro, Centro de Letras e Artes. Faculdade de Letras, Pós-graduação, Ano IX, nº 11, 2004.

DAMAZIO, Reynaldo. Nono livro sintetiza todo o universo simbólico do poeta. Folha de São Paulo. Livros. São Paulo-SP, 14 nov. 1993.

VIEIRA, Tania Regina; AGUIAR. A (re)criação do idioleto manoelês. Rev. Let., São Paulo, v.49, n.1, p.928, jan./jun. 2009. 